\title{
Innovation and Practice of Laser Technology Application Talents Training under the Background of Industry University Research
}

\author{
Zhijuan Sun ${ }^{*}$, Jian Huang \\ Shenzhen Institute of Technology, Shenzhen 518000, Guangdong Province, China
}

\begin{abstract}
In the current context, the society pays more attention to vocational education, requiring technical colleges to cultivate a group of high-quality skilled talents with solid theory, strong professional ability and good professional quality. With the rapid development of laser technology, more detailed requirements are put forward for the training of laser technology application professionals. In order to meet the current situation of social development and realize the comprehensive development of talents in many aspects, technical colleges can introduce the production study research mode in the cultivation of laser technology application talents, and promote the teaching development with the help of new teaching methods, so as to fully guarantee the students' future employment and further study. This paper explores the innovation and practice of laser technology application talents training under the background of industry university research, and puts forward relevant views, in order to improve the teaching effect and realize the win-win situation between school and enterprise.
\end{abstract}

Key words: Industry-university-research cooperation; Application of laser technology; Research on talent cultivation

Publication date: December, 2020

Publication online: 31 December, 2020

"Corresponding author: Zhijuan Sun, 981533038@ qq.com

\section{Introduction}

Industry university research is no longer a new concept. As an effective way to promote the innovation achievements of technical colleges and enterprises, this mode has closely linked enterprises and technical colleges at the beginning of its introduction. In order to meet the needs of social development, Shenzhen Institute of Technology took the lead in setting up the specialty of laser technology application (formerly known as photoelectric technology application) in 2001. In the following years, most of China's technician colleges have set up photoelectric technology specialty. However, due to some internal factors, such as the limited area of training room, incomplete teaching equipment, imperfect training courses and untimely updating of training equipment, it is difficult for technical colleges to meet the needs of talent training in a real sense. Combined with this situation, the introduction of industry university research mode can improve these problems. Through the effective combination of school and enterprise, the enterprise can become the school's off campus training base, which can provide the necessary training equipment and venues for the school, while the school can cultivate more highquality talents for the enterprise, so as to achieve a win-win situation between school and enterprise.

\section{The strategy of the integration of industry university research mode and laser technology application}

The introduction of industry university research mode can promote the development of laser technology application teaching in technical colleges and realize the improvement of students' comprehensive ability. At the same time, the introduction of this teaching mode also innovates the traditional teaching mode 
to a certain extent, and closely combines education with practical production. Combined with the data in recent years, the introduction of industry university research mode is the necessary path for the innovation of laser technology application education mode in China.

\subsection{Optimizing talent training mode}

Under the background of the continuous development of the current society, traditional teaching has been difficult to meet the development needs of professional talents in technical colleges. Relevant enterprises and departments put forward higher requirements for the comprehensive ability of talents, and fully guarantee the future development of students. More and more technical colleges begin to introduce the production study research mode into teaching, so as to cultivate a number of future oriented applied talents Technical and skilled talents. From the perspective of both sides' development, the industry university research mode based on the cooperation between technical colleges and relevant enterprises is a new teaching mode to realize the combination of specialty and education, and win-win between education and employment. It can meet the needs of the current society for comprehensive talents and realize the development of students' multiple abilities. Combined with the educational nature of technical colleges, this mode can implement the training objectives of laser technology application talents, promote the ability of students with the help of novel contents and methods, optimize the talent training mode, and fully guarantee the future development of students.

\subsection{Improving the teaching content and curriculum system}

The introduction of industry university research mode can provide reference for the adjustment of teaching content and curriculum of laser technology application specialty in technical colleges. The school can be combined with the relevant standards of enterprises, and improve on the basis of traditional courses, so as to make the cultivation of post ability more in line with the actual needs. At the same time, the introduction of this mode will expand the scope of laser technology application personnel training system,ensure the development of students' professional ability and quality, so that students can apply the theoretical knowledge to practical training and practice, and the enterprise environment can better cultivate students' professional quality. In this way, students can not only understand the advanced laser technology application field knowledge, familiar with the laser machine assembly and adjustment process, master laser welding,laser cutting,laser marking and other professional skills, their comprehensive ability has been effectively improved,and the teaching effect is more remarkable. In addition, professional teachers can also go deep into enterprises, further clarify the professional processing standards and enterprise talent needs, and timely adjust the teaching direction combined with these contents,so as to make the planning of teaching content and curriculum system more professional and targeted.

\subsection{Injecting fresh vitality into the construction of modern teaching staff}

The construction of modern teaching staff is an important prerequisite for the development of laser technology application teaching. In the past laser technology application teaching, teachers mainly carry out classroom teaching and practical activities, but it can not fundamentally improve students' professional ability and professionalism. In the mode of production, study and research, excellent craftsmen of enterprises can participate in each teaching link, impart their own experience to students, and realize the optimization of teaching staff in the school. The teachers of our school can also communicate with the technical talents of enterprises. They can have a deeper understanding of the technical requirements of enterprises for employees and grasp the key points of production practice. In the whole mode of production, study and research, through the communication with technical personnel, teachers can have a new understanding of teaching content and methods, and can promote the development of laser technology application to a certain extent.

\section{Strategy of laser technology application talents training under the background of industry university research}

\subsection{Making clear the goal of talent training}

In vocational education, the fundamental task is to master students' professional knowledge and skills and cultivate their professional quality, so 
that they can make their own contributions to social development. Therefore, the primary research object under the mode of industry university research is the negotiation between technical colleges and laser technology related enterprises, so as to clarify the talent training objectives. In the context of the continuous development of the current society, combined with the requirements of relevant departments for the comprehensive ability of talents and the development needs of students, it is not difficult to find that in order to better devote themselves to the post, the students of laser technology application major should not only have a solid theoretical foundation, but also have strong practical ability and professional quality. Therefore, technical colleges and universities should strengthen cooperation with enterprises, build a platform for teachers and technicians with the help of industry university research mode, clarify the talent training objectives of both sides, promote the development of students' multiple abilities, and fully guarantee their subsequent learning and employment. Relatively speaking, the clear goal of talent training is the innovation of integrating the mode of production, study and research into the talent training of laser technology application, and it is also the inevitable development of improving the effect of teaching practice.

In the mode of production, study and research, we can start from the following points to clarify the goal of talent training. On the one hand, excellent technical personnel of enterprises communicate with teachers, combined with the specific learning ability of professional students and enterprise talent demand. This requires teachers to integrate the information of students' academic performance and practical ability before making clear the teaching objectives, and plan the next teaching process combined with these contents. In the whole research process, we need to refer to the opinions of both sides, such as some operational activities need to clear what content, through the joint exploration of both sides, so as to clear the teaching goal of each link, so as to promote the development of teaching. On the other hand, professional teachers should always pay attention to the development and change of professional market, adjust the teaching objectives accordingly, and make the teaching content more targeted.

\subsection{Optimizing the curriculum system based on the mode of production, study and research}

Under the mode of industry university research education, laser technology application specialty needs to innovate in the past curriculum structure, and consider more points to improve the curriculum system structure.Combined with the current education requirements and personnel training needs, the improvement of the curriculum needs to be based on the post requirements of laser technology application, build a curriculum system of knowledge theory training, professional skills strengthening and professional quality improvement,and implement the teaching ideas such as craftsman spirit and humanistic concept, so as to cultivate a group of laser technology talents who are willing to work hard, have the courage to explore and dare to innovate in the new era use professionals. In this way,students can enter the post in the future,can have a certain professional work ability,can combine their own development needs, put personal development into the track of enterprise development, and realize their own value in the process of promoting enterprise development.

Combined with the actual development needs,we can adjust the curriculum system in the past, and add the relevant content of industry university research mode. After years of teaching reform of laser technology application specialty in Shenzhen Institute of Technology, the professional courses are mainly integrated courses and project courses.Under the first mock exam mode, the curriculum system of laser technology can break the limitation of single mode and enrich teaching contents. Generally speaking, the system takes the semester as a unit, which is divided into four frameworks, and the school reasonably arranges the class hours according to the development needs. The first framework is mainly theoretical knowledge explanation, which can innovate on the basis of explaining the application knowledge of laser technology, and add craftsmanship spirit, professional development trend and other contents. The second stage mainly explains the basic technology, which can be improved according to the data provided by enterprises, so that students can master the application of advanced laser technology at home and abroad. The third stage is the development of professional ability, in which the relevant enterprise standards can be added, and students operate in strict 
accordance with the standards. The fourth stage emphasizes the integration of theory and practice, school teachers and enterprise technicians participate in teaching activities together. In this way, through the optimization of the curriculum system, we can further realize the development of students' ability, and fully reflect the guiding role and practical value of the industry university research model.

\subsection{Strengthening information exchange and cultivating modern talents}

In order to achieve a win-win situation between enterprises and schools, both sides need to strengthen information exchange on the basis of cooperation. In the context of industry university research,laser technology application enterprises should pay attention to knowledge exchange activities, play their own role of site value, provide learning platform for students, and promote the development of students' comprehensive ability. To provide teachers with a field learning site, so that teachers can have a certain understanding of the application of new laser technology, and apply it to the teaching process. At the same time, teachers can also understand the ability requirements of enterprises for talents, so as to adjust the teaching direction and reasonably plan the teaching content.For technical colleges, it can provide enterprise researchers with opportunities for further study.Relevant enterprises regularly arrange relevant personnel to study in schools,master more theoretical knowledge,explore management contents with school teachers, and apply these contents to team optimization.

\subsection{Optimizing evaluation mechanism based on industry university research mode}

Evaluation is an important part of vocational education, which is an important content for teachers to find reference value and students to identify their own problems. Under the background of industry university research, the evaluation system of laser technology application specialty teaching needs to be further improved. It can be divided into two evaluation contents, which constitute a complete evaluation system. First of all,the enterprise training stage,by the enterprise talents and department experts to carry out evaluation, according to the students' knowledge application ability, practice stage results, training attitude and quality evaluation. This content accounts for $40 \%$ of the total score.

Secondly, the overall performance evaluation,by the school teachers and enterprise talents as the main body of evaluation, combined with students' classroom learning performance,task completion,participation enthusiasm and other content evaluation. This content accounts for $60 \%$ of the total score. Through the optimization and improvement of the evaluation mechanism, we can give play to the participation and role of enterprises in student evaluation to a certain extent, and teachers can adjust the teaching direction in time according to the evaluation situation of students.

\section{Conclusion}

In conclusion, the application of industry university research mode in the teaching of laser technology application specialty can improve students' ability and promote the development of teaching. Therefore, technical colleges and teachers need to proceed from reality,pay attention to the cooperation between professional teaching and enterprises,so as to promote the development of students' ability,and enterprises can also obtain more high-quality talents to achieve win-win cooperation.

\section{References}

[1] Huang QF, Wu PP. Discussion on ways and methods of cultivating high skilled talents under the background of industry education integration $[\mathrm{J}]$. Theoretical Research and Practice of Innovation and Entrepreneurship, 2019(10): 183184.

[2] Le CN. Research and practice of chemical engineering courses integrating production, learning, research and innovation in secondary vocational schools [J]. Equipment Manufacturing Technology, 2020(2): 162-165 + 169.

[3] Chen YY. Analysis on the practical teaching of production, study and research investigation of secondary vocational accounting specialty $[\mathrm{J}]$. College Entrance Examination, 2019(27): 29.

[4] Huang HL, Lu XR, Ao X. Exploration on the construction and implementation of industrial and academic cooperative laser machining teaching $[\mathrm{J}]$. China Modern Educational Equipment, 2019, 311(7): 107-109. 